\title{
Sound Transmission Loss of a Metal Panel With Rib Reinforcements and Pasted Damping
}

\author{
Xin-Xing Xie \\ School of Mechanical and Automotive Engineering, South China University of Technology, Guangzhou 510641, \\ P.R. China. \\ Ningbo Tuоpu Group Co., Ltd., Ningbo 315800.
}

\section{Zhong-Xiang Yuan and Wen-Bin Shangguan}

School of Mechanical and Automotive Engineering, South China University of Technology, Guangzhou 510641, P.R. China.

(Received 4 March 2020; accepted 29 August 2020)

\begin{abstract}
The sound transmission losses (STL) of a metal panel with rib reinforcement (MPRR) are studied by both an experimental method and a simulation approach. The experimental method and data processing technique for obtaining STL are presented. Six MPRRs with different number of rib reinforcement and different geometry size of rib reinforcement, and six MPRRs with different type of the pasted damping material are designed and manufactured, and their STL performances are investigated by experimental method. The calculation model for STL of a MPRR is proposed and the calculated STL are compared favorably with the experimental data, which validates the proposed model. The analytical methods and conclusions are instructive for the design and the tuning of STL of MPRRs.
\end{abstract}

\section{INTRODUCTION}

Sandwich panels are widely used in industries of aircraft and automotive structures ${ }^{1,2}$ and sound transmission loss (STL) is an important measure to evaluate performances of sandwich panels. A metal panel with rib reinforcement (MPRR) is a type of sandwich panel and is widely used in a car to enhance STL of a car body. Comparing to the conventional sandwich panels, one of the advantages of a MPRR is that it can reduce the weight of a structure, enhance the structure's stiffness, and reduce structural vibrations and related structure-borne noise. In automotive industries, the MPRRs are used as parts of a component, such as supporters of dash panel and carpet, and the STL of a MPRR will influence the sound insulation performance of the dash panel or carpet in cars.

At present, the influence of a MPRR on the sound insulation performance of car cabin does not pay much attention, which led some errors between the calculated results and experimental data of the dash panel. ${ }^{3,4}$ In designing a MPRR, engineers are mainly concerned about its stiffness. Now, it is well developed to study the influence of shape and size of rib reinforcement on the stiffness of a metal panel. Therefore, to develop procedures and methods for estimating STL of a MPRR are important for engineers. It is concluded from $\operatorname{Refs}^{5-7}$ that some researchers of studying MPRR focus on the solid rib reinforcement structure and rectangular cross section, and the influences of rib numbers and pasted damping on STL of MPRRs used in automotive industries are not fully understood. Also, the calculation methods and experimental results for obtaining STL of a MPRR are not readily available in present published references.
Therefore, the chief objectives of this article are to disclose influences of different number of rib reinforcement, different geometry size of rib reinforcement and different types of pasted damping on the STL of the MPRRs by experiments, and to establish methods to calculate the STL of a MPRR and a MPRR with pasted damping.

There is a substantial body of literature on estimation of the sound insulation performances of sandwich panels. For example, the work of Nilsson et al. on the bending motion of a sandwich structure, and the use of an apparent bending stiffness to compute their sound transmission coefficient. ${ }^{8-10}$ Moreover, this latter homogenisation approach was also used to investigate sandwich panels as equivalent orthotropic panels using the transfer matrix method, ${ }^{11,12}$ a relevant approach to compute the sound transmission loss of multilayer systems. The STL of a sandwich panel depends on the characteristics of two surface layers, middle layer or core and supported boundary conditions. Arunkumar et $\mathrm{al}^{13}$ studies the STL of a sandwich panel with a honeycomb core. The influences of the honeycomb shape and size on the STL at low and high frequencies are studied numerically. Wen et $\mathrm{al}^{14}$ measured and estimated STL of sandwich panels with different types of cores in the frequency range of $200 \mathrm{~Hz}$ to $1600 \mathrm{~Hz}$. The influences of four types of cores, namely orthogonal corrugated core, semi layer core, a quarter of closed octahedral lattice structure and unit cell, and the sizes for each core on STL of sandwich panels are studied. The STL of a sandwich panel with a four-side simply supported boundary is investigated numerically and the calculated data is validated using the estimated results from FEM/BEM. ${ }^{15}$ Influences of some key parameters, such as thickness of each layer, damping of core, elastic modulus, and incident angle, 
on STL are studied using the developed model. In addition, some researchers studied the acoustic performances of cylindrical shells and double-walled plates through experimental and analytical method. ${ }^{16-18}$ In contrast, metal panels with rib reinforcement (MPRR), or MPRRs, with pasted damping are seldom studied for its sound insulation and transmission characteristics to the best of the author's knowledge.

To predict STL of a sandwich panel at different frequency ranges, different calculation methods are used. In different frequency range, a sandwich panel exhibits different STL, and methods used for estimating STL of a sandwich panel are classified into three types:

(1) Deterministic analysis methods: This method is suitable for low-frequency to mid-frequency STL analysis, and the commonly used methods are finite element analysis (FEA) and boundary element method $(\mathrm{BEM})^{19-22}$ etc. Moreover, highorder adaptive method, ${ }^{23}$ stability method ${ }^{24}$ and multi-scale method $^{25}$ etc., are all included to the deterministic methods.

(2) The statistical energy analysis (SEA) method: The SEA method is used for estimating the STL of a body at high frequency ranges, and one more detailed theoretical derivation is obtained in Ref. ${ }^{26,27}$ Based on the conventional SEA method, some generalized SEA methods were proposed. The approaches include wave analysis method, ${ }^{28}$ modal energy distribution statistical analysis, energy finite element method and dynamic energy analysis. ${ }^{29}$

(3) Hybrid method: This method combines deterministic methods and statistical methods to analyze STL at midfrequency. In Ref., ${ }^{30} \mathrm{Ji}$ et al. summed up all kinds of approaches for predicting mid-frequency vibration in the past twenty years. The first categories of methods are the combination of the FEA method with other nondeterministic methods, and different hybrid methods can be established by using various nondeterministic methods. The hybrid FE-SEA method is a combination of the conventional FEA and the SEA method. ${ }^{31,32}$ If the SEA method is replaced by other nondeterministic methods, then a novel mixed approach is formed. If the FEA method is replaced with a deterministic method, such as boundary element method (BEM), then the hybrid BE-SEA method is formed.

In summary, the deterministic analysis method can predict STL with high accuracy in the low frequency range. Since many degrees of freedoms and dense modes existed in the high frequency domain, and if deterministic analysis method is used for estimating STL, it will take a long calculation time with lower calculation accuracy and with difficulties for convergences. Since the SEA method takes the assumption of weak coupling and many modal parameters into account, the SEA method is suitable for estimating STL at high frequency ranges. The hybrid methods, such as the hybrid FESEA method, using the advantages of the deterministic analysis methods and the SEA methods, can predict sound insulations at mid-frequency range.

The STL of a dash panel, carpet and body in a car are determined by sound insulations of MPRRs for each part to some extends. A MPRR is made of a metal panel and rib reinforcements by welding. Although the MPRRs used in a car are com- plicated, the structure of a MPRR is simplified here without affecting the basic regulation of sound insulation of a MPRR.

In this paper, six MPRRs with different numbers of rib reinforcements and different geometry sizes of rib reinforcements are designed, manufactured, and numbered as MPRR I to MPRR VI. The metal panels for the six MPRRs are identical and the only differences of the six MPRRs are the number of rib reinforcements and size of rib reinforcement. In order to obtain the influences of a pasted damping material on the STL of a MPRR, six MPRRs with different pasted damping are designed and manufactured, and the schemes are numbered as Scheme I to Scheme VI. The MPRRs for the six schemes are identical and the only differences are the damping coverage area ratio and damping position. The objectives of this study are to disclose the influences of the MPRRs on sound insulation performance by experimental methods and to establish the calculation model for a MPRR using commercial software VA-One and to validate the model by comparing simulation and experiment.

The organization of this paper is as follows: in Section 2, the basic principle of the sound insulation measurement is briefly described, and different MPRRs and different MPRRs with pasted damping are designed, and the sound insulation performance for different schemes are measured and discussed. In Section 3, the calculation model for a MPRR is developed and validated by experiment, and the sound insulation performances of different MPRRs are simulated using the model. Finally, a summary is given in Section 4 to conclude this work.

\section{MEASUREMENT OF STL FOR A MPRR}

\subsection{Experimental Method}

A metal panel with rib reinforcement (MPRR) was used to measure sound insulation using the reverberation-anechoic chamber method as recommended in Refs. ${ }^{33-35}$. The installation for a MPRR is shown in Fig. 1.

The MPRR was installed on the window between the reverberation chamber and the anechoic chamber. The reverberation chamber was used as the source chamber and sound sources (loudspeakers) were placed in the chamber. The anechoic chamber was used as the receiving chamber. Before the experiment, a MPRR was clamped between the wall of the reverberation chamber and the anechoic chamber using eight bolts and rubber gaskets were placed in the gap between the wall and the MPRR to insulate the sound transmission through the gap and to avoid the resonance of the MPRR at high frequency. This kind of installation for the MPRR was defined as a free boundary condition.

Two loudspeakers were placed diagonally in the reverberation room to generate sound sources, and five microphones (B\&K2669) were used to measure mean square value of sound pressures of multi-points in the reverberation chamber. The mean square value of sound pressures was estimated using:

$$
\bar{p}=\sqrt{\frac{1}{5} \sum_{i=1}^{5} p_{i}{ }^{2}} ;
$$




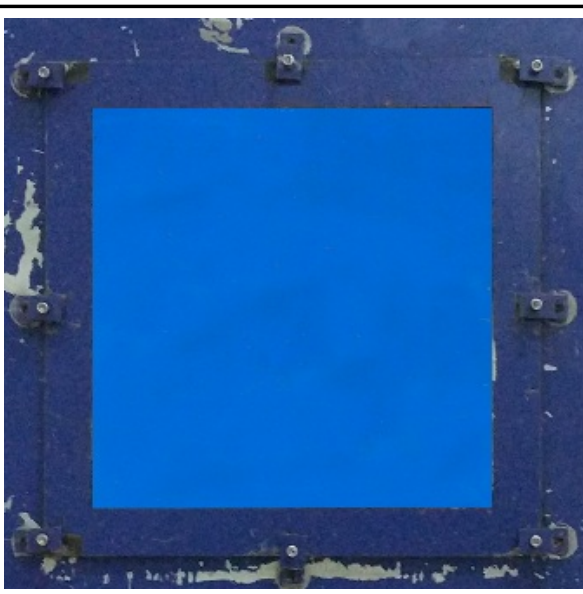

(a)

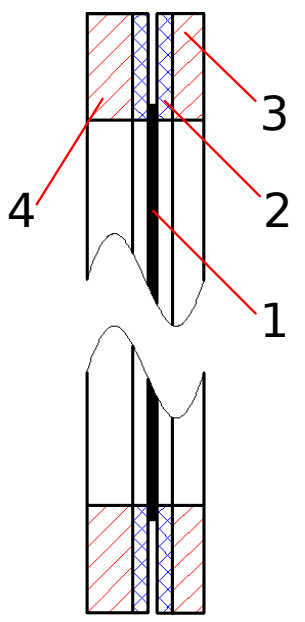

(b)

Figure 1. Diagram for MPRR installation: (a) MPRR installation; (b) Sectional view for MPRR installation. 1 - MPRR; 2 - rubber gasket; 3 - clamped panel; 4 - sound insulation wall.

Table 1. The parameters of the chambers

\begin{tabular}{|l|l|l|l||}
\hline Chamber & Volume $\left(\mathrm{m}^{3}\right)$ & $\begin{array}{l}\text { Cutoff frequency } \\
(\mathrm{Hz})\end{array}$ & $\begin{array}{l}\text { Background } \\
\text { Noise }(\mathrm{dB})\end{array}$ \\
\hline $\begin{array}{l}\text { Anechoic } \\
\text { chamber } \\
\text { Reverberation } \\
\text { chamber }\end{array}$ & $4.8 \mathrm{~m} \times 4.5 \mathrm{~m} \times 4.2 \mathrm{~m}$ & 100 & 20 \\
\hline
\end{tabular}

where $p_{i}(i=1,2,3,4,5)$ was the sound pressure value of the reverberation room measured at one point by the five microphones, and $\mathrm{p}$ was the mean square root value of multi-point sound pressure in the reverberation room. The positions for the five microphones in the reverberation chamber are shown in Fig. 2. The sound intensity of the MPRR was measured by using a sound intensity probe (B\&K3599) to scan the surface of the MPRR at the side of the anechoic chamber which is shown in Fig. 3. The related parameters of anechoic chamber and reverberation room are shown in Tab. 1.

During experiment, the distance between the sound intensity probe and the MPRR was equal to $30 \mathrm{~mm}$, and the scanning paths included the lateral paths and the vertical paths, as shown in Fig. 4, for finding averaging value of sound intensity.

According to the ISO standard, ${ }^{35}$ the sound intensity probe should be placed $0.1 \mathrm{~m}$ to $0.3 \mathrm{~m}$ from the measured body. In

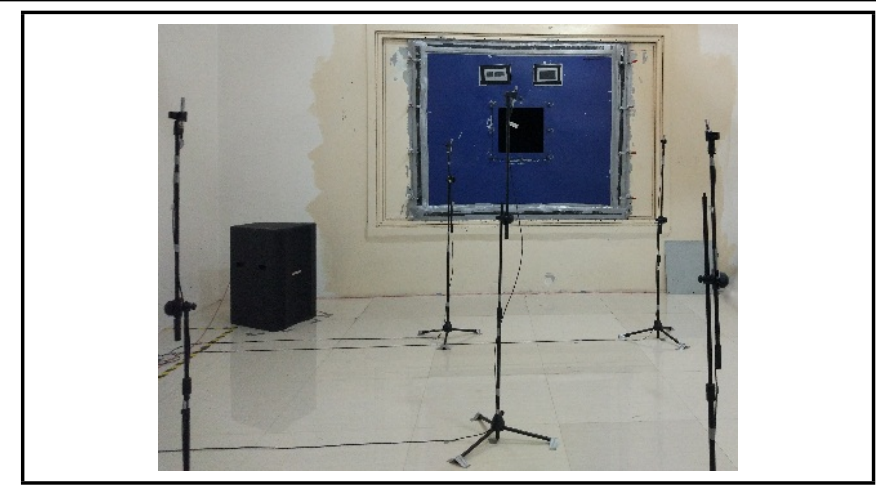

Figure 2. Microphones position.

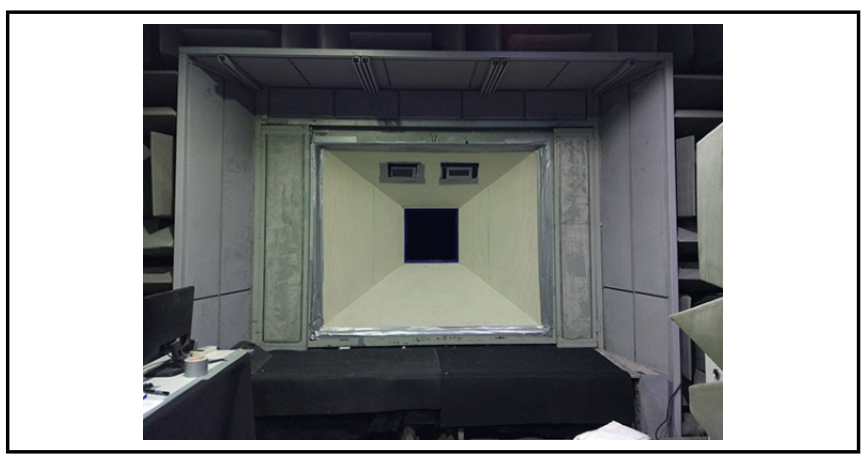

Figure 3. Measurement of sound intensity for MPRR at Anechoic chamber.

this experiment, the sound intensity probe was placed from $30 \mathrm{~mm}$ to $0.3 \mathrm{~m}$ from the measured MPRR, but the measured results were the same. The sound intensity probe was $30 \mathrm{~mm}$ away from the MPRR samples in our studies. As shown in Fig. 4(a), the lateral paths included multiple horizontal paths that were parallel to each other and a semi-circular path existed between one end of the adjacent horizontal paths and the opening face to the horizontal direction. The vertical paths, as shown in Fig. 4(b), included some parallel vertical paths and a semi-circular path existed between one end of the adjacent vertical paths and the opening face to the vertical direction.

In the reverberation chamber, the sound sources were radiated randomly on the MPRR. The incident sound powers on the MPRR were calculated using the measured average sound pressure of the reverberant sound field, and was given by

$$
W_{i n}=\frac{\bar{p}^{2}}{4 \rho c} S ;
$$

where $S$ was the surface area on the source side of the MPRR, $\rho$

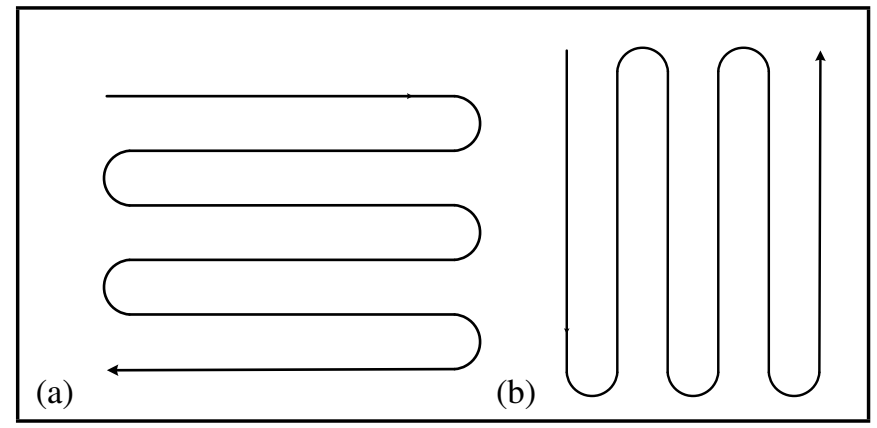

Figure 4. Scanning paths of sound intensity: (a) Lateral paths; (b) Vertical paths. 


Table 2. Structural parameters for MPRR I to MPRR IV (L=505mm).
\begin{tabular}{|l|l|l|l|l|l|l|l|}
\hline $\begin{array}{l}\text { Scheme } \\
\text { number }\end{array}$ & $\begin{array}{l}\text { a } \\
(\mathrm{mm})\end{array}$ & $\begin{array}{l}\mathrm{b} \\
(\mathrm{mm})\end{array}$ & $\begin{array}{l}\mathrm{c} \\
(\mathrm{mm})\end{array}$ & $\begin{array}{l}\text { Thickness } \\
(\mathrm{mm})\end{array}$ & $\begin{array}{l}\text { Density } \\
\left(\frac{\mathrm{kg}}{\mathrm{m}^{3}}\right)\end{array}$ & $\begin{array}{l}\text { Number } \\
\text { of ribs }\end{array}$ & Perforated \\
\hline I & 20 & 20 & 70 & 1.3 & 7850 & 1 & no \\
II & 20 & 80 & 70 & 1.3 & 7850 & 1 & no \\
III & 20 & 30 & 50 & 1.6 & 7850 & 1 & no \\
IV & 20 & 30 & 90 & 1.6 & 7850 & 1 & no \\
V & 20 & 30 & 90 & 1.6 & 7850 & 1 & yes \\
VI & 20 & 30 & 90 & 1.6 & 7850 & 3 & no \\
\hline
\end{tabular}

and $c$ were the density and sound speed in the air, respectively.

In the anechoic chamber, the transmitted sound powers were calculated using the measured sound intensity with the scanning method. The MPRR was scanned uniformly to obtain the sound intensity, and then the transmitted sound power was obtained by multiplying the sound intensity $(I)$ and the surface area $(S)$ on the reception side of the MPRR: ${ }^{33}$

$$
W_{\text {out }}=I S \text {. }
$$

The sound transmission loss (STL) of the MPRR was calculated by substituting incident sound powers and transmitted sound powers into the STL formula, ${ }^{33,36}$ and was expressed as:

$$
S_{T L}=10 \log _{10}\left(\frac{E_{\text {in }}}{E_{\text {out }}}\right)=10 \log _{10}\left(\frac{\bar{p}^{2} S / 4 \rho c}{I S}\right) .
$$

Finally, substituting the density and sound speed of the air into the Eq. (4), the STL of the MPRR in the reverberationanechoic chamber was:

$$
S_{T L}=\bar{L}_{P}-\bar{L}_{I}-6 ; \quad(\mathrm{dB})
$$

where the $\mathrm{S}_{\mathrm{TL}}$ was the STL of the MPRR, the $\bar{L}_{P}$ was the average sound pressure level of the reverberation chamber, and the $\bar{L}_{I}$ was the average sound intensity level of the anechoic chamber.

\subsection{Tested Objects}

The rib reinforcement factors including the height and width, holes and number of rib reinforcements on metal panels (steel) were taken into account on the investigation of the sound insulation of MPRRs in the dash panels and carpets used in cars. Six MPRRs with different numbers of rib reinforcements and different geometry sizes of rib reinforcements were designed and manufactured. The metal panels for the six MPRRs were identical and the only differences of the six MPRRs were the number of rib reinforcements and sizes of rib reinforcements. The base metal panel for the six MPRRs were the same and its length, width, and thickness measurements were $505 \mathrm{~mm}, 505 \mathrm{~mm}$, and $1 \mathrm{~mm}$, respectively. The structures and layouts for MPRR I to MPRR IV are shown in Fig. 5, the layout for MPRR V is shown in Fig. 6 and the layout for MPRR VI is shown in Fig. 7. The geometry sizes of rib reinforcement for each MPRR are shown in Tab. 2.

\subsection{Measured STL for Different Types of MPRR}

The distance between the sound intensity probe and the measured body is $1 / 2$-inch and the sound intensity probe can be

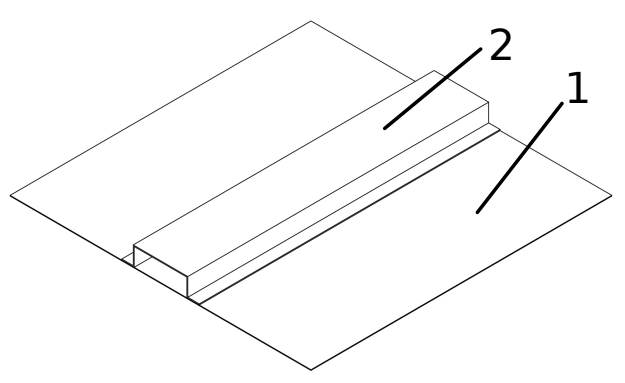

(a)

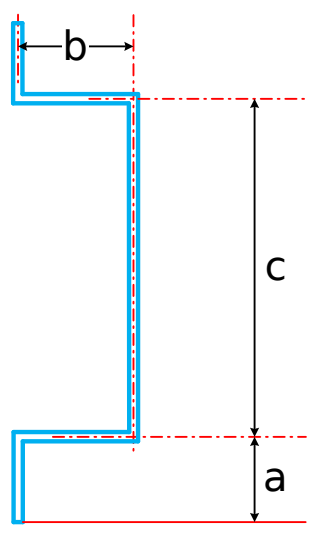

(b)

Figure 5. MPRR I to MPRR IV: (a) Diagram for MPRR I to MPRR IV; (b) Parameters of the rib reinforcement.

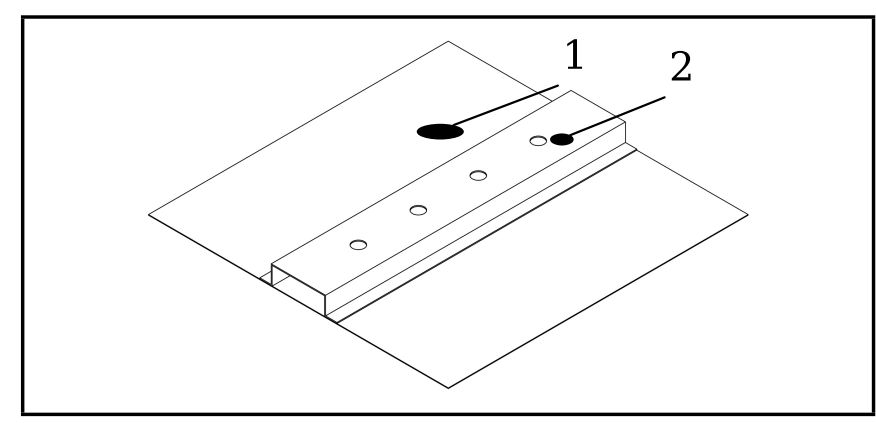

Figure 6. MPRR V. 1 - metal panel; 2 - rib reinforcement.

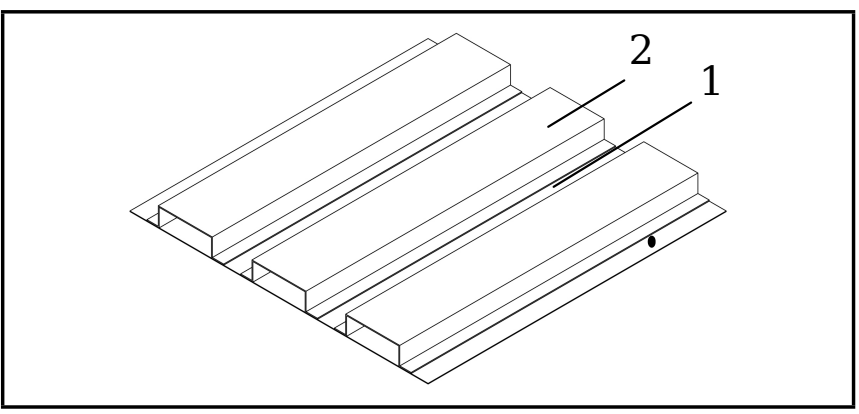

Figure 7. MPRR VI: Schematic diagram for MPRR VI. 1 - base metal panel; 2 - rib reinforcement. 
Table 3. Comparison plans for influences of rib reinforcement on STL.

\begin{tabular}{|l|l|l|}
\hline Factors & $\begin{array}{l}\text { Baseline } \\
\text { scheme }\end{array}$ & $\begin{array}{l}\text { Scheme to be } \\
\text { compared }\end{array}$ \\
\hline Height of rib reinforcement & MPRR I & MPRR II \\
Width of rib reinforcement & MPRR III & MPRR IV \\
Holes in rib reinforcement & MPRR IV & MPRR V \\
Number of rib reinforcement & MPRR IV & MPRR VI \\
\hline
\end{tabular}

used for $1 / 3$ octave center frequency test from $20 \mathrm{~Hz}$ to 6.3 $\mathrm{kHz}$. In the design of automotive dash panel systems, the focused frequencies are usually ranged from $400 \mathrm{~Hz}$ to $4000 \mathrm{~Hz}$, so the analytical frequency ranges are assumed to range from $400 \mathrm{~Hz}$ to $4000 \mathrm{~Hz}$ in this study. Six metal panels with rib reinforcement (MPRRs) were designed and manufactured, and their STLs were measured in the reverberation-anechoic chamber. Different MPRRs used for analyzing the influences of rib reinforcement on sound transmission loss (STL) are shown in Tab. 3 .

The sound insulation performance for different MPRRs with different numbers of rib reinforcement and different geometry sizes of rib reinforcements were measured using the methods described in section 2.1. The experimental data of STL for different MPRRs were then given and compared. The factors, including height of rib reinforcement, width of rib reinforcement and holes in rib reinforcement as well as number of rib reinforcement are investigated in this paper.

(1) Effects of height and width for rib reinforcement on STL

The measured STL of the MPRRs with different heights of rib reinforcement and different widths of rib reinforcement are shown in Fig. 8

By comparing MPRR II with MPRR I in Fig. 8(a), it was concluded that, as height of the rib reinforcement increased, the STL increased by $1 \mathrm{~dB}$ on average in the frequency range of $400 \mathrm{~Hz}$ to $580 \mathrm{~Hz}$, and $1200 \mathrm{~Hz}$ to $2500 \mathrm{~Hz}$, respectively. However, in the frequency range of $580 \mathrm{~Hz}$ to $1200 \mathrm{~Hz}$, and $2500 \mathrm{~Hz}$ to $4000 \mathrm{~Hz}$, the STL decreased by $1 \mathrm{~dB}$ on average.

By comparing the STL of MPRR IV with MPRR III, it is seen from Fig. 8(b) that the STL increased by an average of $1.2 \mathrm{~dB}$ in the whole frequency range as the width of the rib reinforcement increased from $50 \mathrm{~mm}$ to $90 \mathrm{~mm}$. The results show that the width of the rib reinforcement had great influences on STL, and the STL increased in the whole range as the width of the rib reinforcement increased. The amplitude of the STL variation was related to the variation of the width of the rib reinforcement.

(2) Effect of holes in rib reinforcement on STL

Fig. 9 shows that STL was reduced if the rib reinforcement is open a hole. In MPRR V, the radius for the holes was equal to $10 \mathrm{~mm}$ and it was uniformly distributed on the rib reinforcement. There were four holes in MPRR V and the area of the holes accounted for $1.31 \%$ of the area of the rib reinforcement. By comparing STL of MPRR V with MPRR IV in Fig. 9, it was concluded that the STL decreased by $0.7 \mathrm{~dB}$ on average in the whole frequency domain. Therefore, the holes in rib reinforcement lead to the decrease of STL, and different areas of the hole in rib reinforcement lead to different changes of the STL.

In automotive industries, there are many rib reinforcements

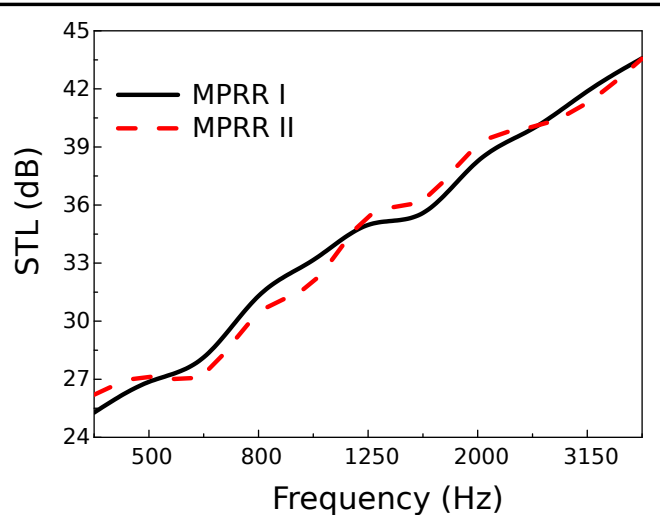

(a)

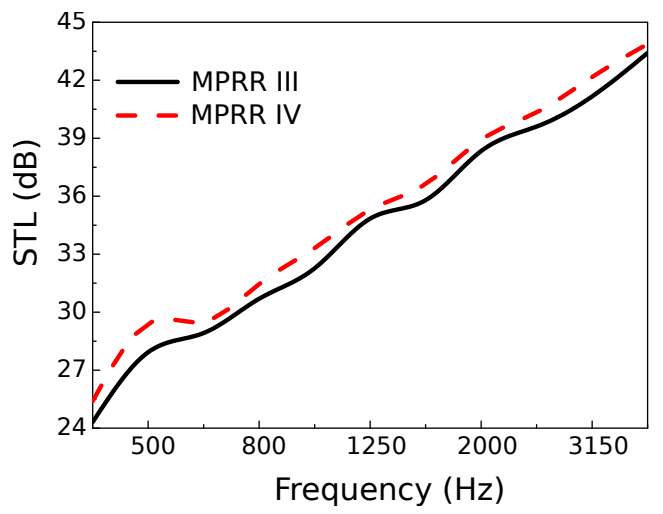

(b)

Figure 8. Influences of height and width for rib reinforcement on STL: (a) Height; (b) Width.

with holes, such as the holes for the wire pathway, the steering column and the air conditioning water pipe, et al. The existence of these holes and some craftwork holes may decrease the STL of a MPRR, and these holes should be avoided to reduce STL.

(3) Effect of number of rib reinforcement on STL

The measured STL for MPRR IV and MPRR VI are shown in Fig. 10. It is seen that, when compared with the STL of MPRR VI, the STL of MPRR IV was reduced considerably in the frequency range of $480 \mathrm{~Hz}$ to $1200 \mathrm{~Hz}$, and $2150 \mathrm{~Hz}$ to $4000 \mathrm{~Hz}$, but the STL increased in the frequency domain of $400 \mathrm{~Hz}$ to $480 \mathrm{~Hz}$, and $1200 \mathrm{~Hz}$ to $2150 \mathrm{~Hz}$. It is also seen from Fig. 10 that a peak data of STL appeared at $630 \mathrm{~Hz}$ for

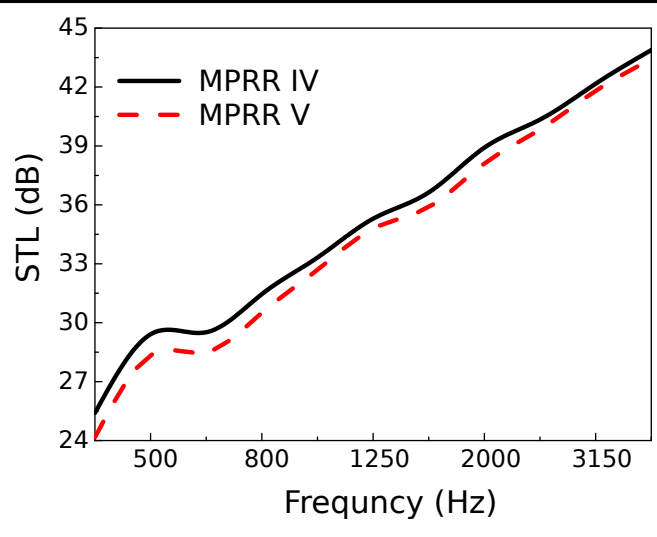

Figure 9. Influence of holes in rib reinforcement on STL. 


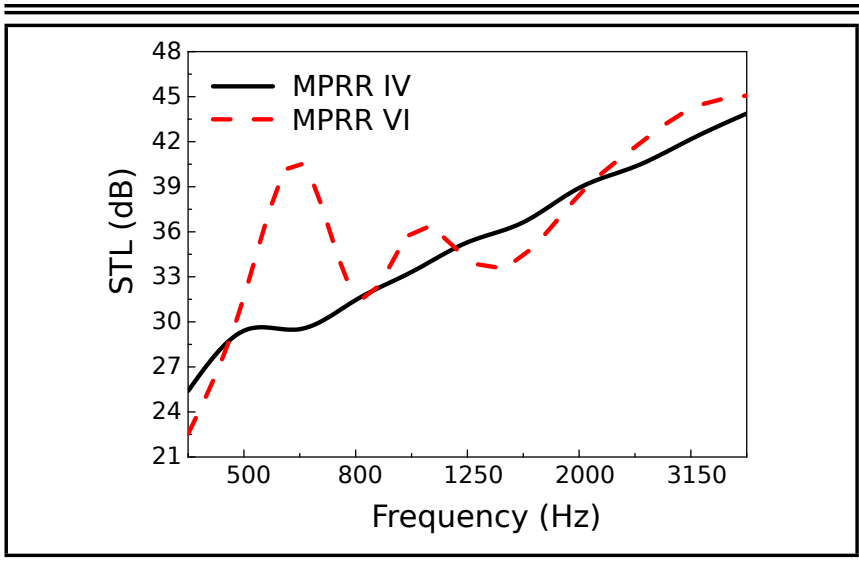

Figure 10. Influence of number of rib reinforcement on STL.

Table 4. Damping locations and coverage area ratios of different schemes.

\begin{tabular}{|c|c|c|}
\hline Schemes & Damping location & Coverage area ratios \\
\hline $\mathrm{I}$ & $\begin{array}{l}\text { damping pasted at rib rein- } \\
\text { forcement }\end{array}$ & $80 \%$ of the rib reinforcement \\
\hline II & $\begin{array}{l}\text { damping pasted at rib rein- } \\
\text { forcement }\end{array}$ & $100 \%$ of the rib reinforcement \\
\hline III & $\begin{array}{l}\text { damping pasted at metal } \\
\text { panel }\end{array}$ & $80 \%$ of the metal panel \\
\hline IV & $\begin{array}{l}\text { damping pasted at metal } \\
\text { panel }\end{array}$ & $100 \%$ of the metal panel \\
\hline V & $\begin{array}{l}\text { damping pasted at metal } \\
\text { panel and rib reinforcement }\end{array}$ & $\begin{array}{l}100 \% \text { of the metal panel and } \\
\text { rib reinforcement }\end{array}$ \\
\hline VI & Baseline (No damping) & \\
\hline
\end{tabular}

the STL of the MPRR VI, and this was due to resonate in the cavity and the resonate direction was opposite to that of the source sound field which acted as a reverse reinforcement with the number of the rib reinforcement increased.

\subsection{Effects of Damping on STL for MPRR}

Both constrained and unconstrained damping treatments are widely used in industries for vibration control. The damping material pasted at a metal panel with rib reinforcement (MPRR) is one effective way to reduce vibration and improve sound insulation performance. The damping can effectively reduce the vibration amplitude of a MPRR, dissipate the vibration energy and reduce the structure-acoustic system's noise. In this section, the MPRR VI was taken as the research object. The damping materials were pasted at the MPRR VI in different positions, and with different coverage area ratio. The coverage area ratio was used as a measure to study the influences of damping on STL of a MPRR. The thickness of the damping material used in the experiment was $2 \mathrm{~mm}$, and the density and loss factors were equal to $1250 \mathrm{~kg} / \mathrm{m}^{3}$ and 0.6 , respectively.

Fig. 11 shows that the damping materials were pasted at the MPRR VI in different positions and had different coverage area ratios. Six schemes of MPRRs with pasted damping materials were designed and manufactured. The MPRR for the six products was identical and the only difference of the six MPRRs with pasted damping materials was the damping coverage area ratio and damping position. Schemes I through VI are shown in Tab. 4, and the STLs were measured by an experimental approach. The damping locations and coverage area ratios of schemes I through VI are shown in Tab. 5.

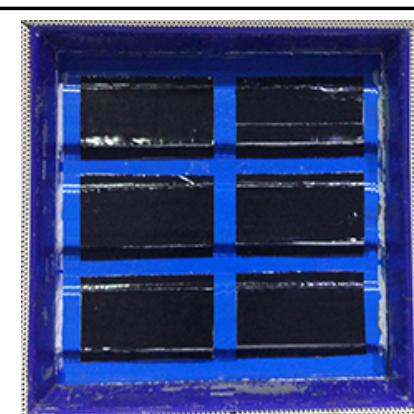

(a)

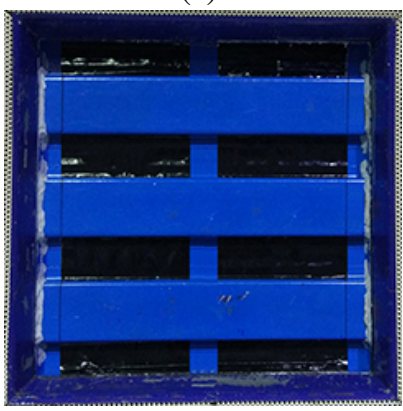

(c)

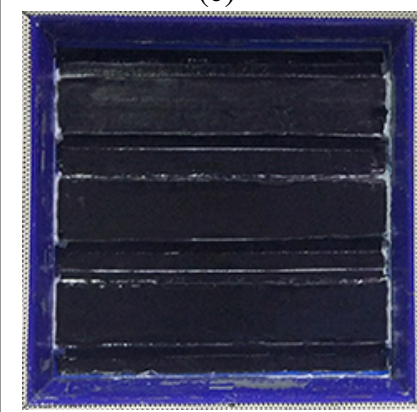

(e)

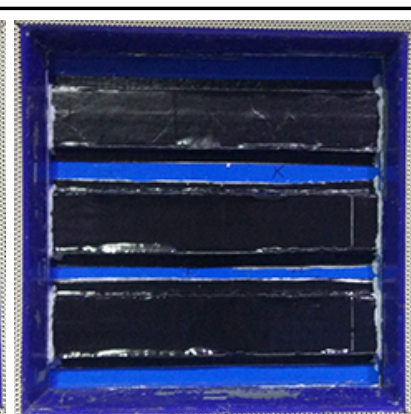

(b)

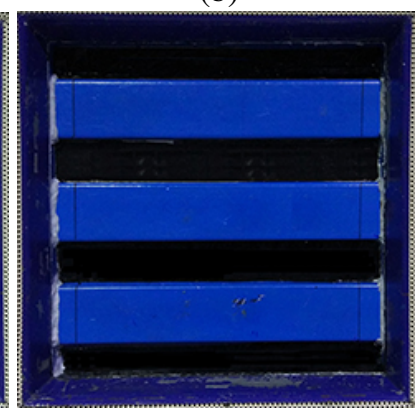

(d)

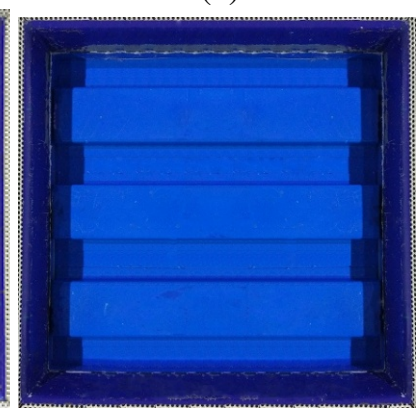

(f)
Figure 11. The MPRR with pasted damping treatments: (a) Scheme I; (b) Scheme II; (c) Scheme III; (d) Scheme IV; (e) Scheme V; (f) Scheme VI.

It is seen from Fig. 11 that the damping treatments in Figs. 11 (a) to (e) were to paste damping at the MPRR in different positions and with different coverage areas, while Fig. 11(f) shows that no damping pasted at the MPRR. Different schemes to analyze influences of damping on STLs are shown in Tab. 5. The factors including different positions that damping applied and different coverage area ratio that damping treatment are investigated in this paper.

\section{(1) Effect of damping pasted at MPRR with different} coverage area on $S T L$

The STL for the damping material pasted at rib reinforcement or metal panel was measured in a reverberation-anechoic chamber, and the experimental values are shown in Fig. 12.

Table 5. Comparison plan for analyzing the influences of damping pasted at MPRR on STL.

\begin{tabular}{|l|l|l|}
\hline Comparison factors & $\begin{array}{l}\text { Baseline } \\
\text { scheme }\end{array}$ & Scheme to be compared \\
\hline Damping coverage area & scheme I & scheme II \\
\cline { 2 - 3 } & scheme III & scheme IV \\
\hline Damping position & scheme I & scheme III \\
\cline { 2 - 3 } & scheme II & scheme IV \\
\hline With or without damping & scheme I & scheme III, scheme VI \\
\cline { 2 - 3 } & scheme II & scheme IV, scheme V, scheme VI \\
\hline
\end{tabular}




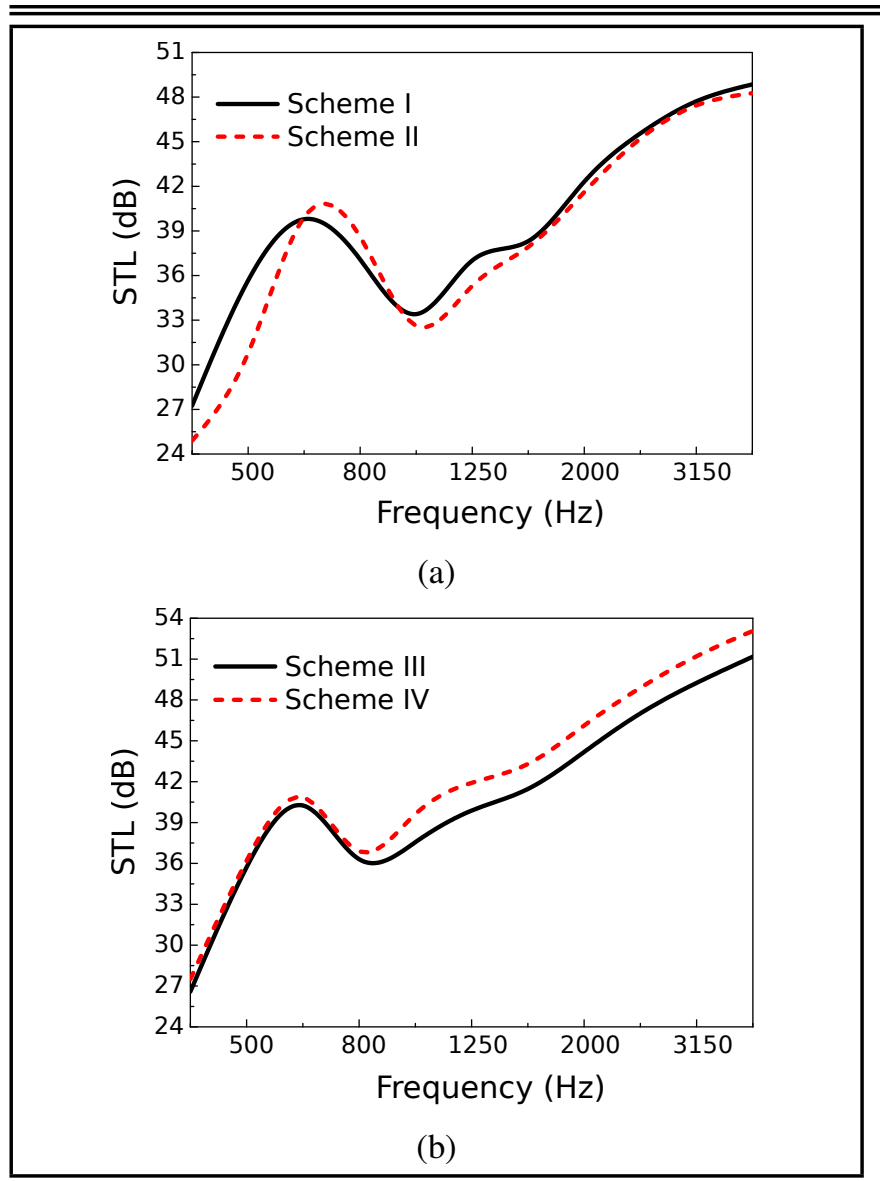

Figure 12. Influences of damping pasted at MPRR with different coverage area on STL: (a) STL comparison of Schemes I and II; (b) STL comparison of Schemes III and IV.

It was observed in Fig. 12(a) that, with damping coverage area ratio increasing, the STL was reduced by $0.5 \mathrm{~dB}$ on average in the frequency range of $400 \mathrm{~Hz}$ to $630 \mathrm{~Hz}$, and range of $900 \mathrm{~Hz}$ to $4000 \mathrm{~Hz}$, but the STL increased by $1 \mathrm{~dB}$ on average in the frequency range of $630 \mathrm{~Hz}$ to $900 \mathrm{~Hz}$.

Fig. 12(b) shows that, as the coverage area ratio of the damping pasted at the metal panel increased from $80 \%$ to $100 \%$, the STL increased by $0.5 \mathrm{~dB}$ on average in the frequency range of $400 \mathrm{~Hz}$ to $800 \mathrm{~Hz}$, and in range of $800 \mathrm{~Hz}$ to $4000 \mathrm{~Hz}$, the STL increase by $2 \mathrm{~dB}$ on average. The experimental results show that the STL increased dramatically when the coverage area ratio rose from $80 \%$ to $100 \%$ if the frequency was greater than $800 \mathrm{~Hz}$. The STL changed a little in low and mid frequency (from $400 \mathrm{~Hz}$ to $800 \mathrm{~Hz}$ ).

(2) Effects of damping pasted at MPRR with different positions on STL

The STL for the damping material pasted at rib reinforcement or metal panel was measured in reverberation-anechoic chamber by an experimental method, and the experimental data is shown in Fig. 13. The coverage area ratio of the damping $(80 \%$ or $100 \%)$ was identical and the only difference between the schemes are the position that damping applied.

By comparing scheme III with scheme I in Fig. 13(a), it was concluded that there was not much of a difference in STL in the range of $400 \mathrm{~Hz}$ to $800 \mathrm{~Hz}$. The STL increased by $2.5 \mathrm{~dB}$ on average in the frequency domain of $800 \mathrm{~Hz}$ to $4000 \mathrm{~Hz}$. Moreover, the experimental results showed that under $80 \%$ coverage area

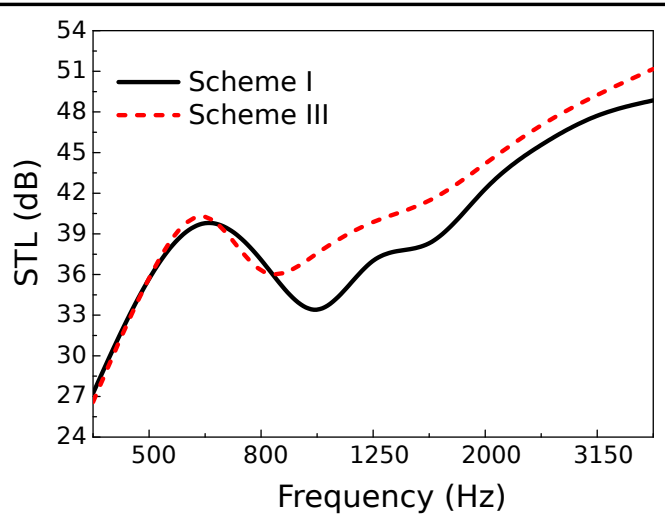

(a)

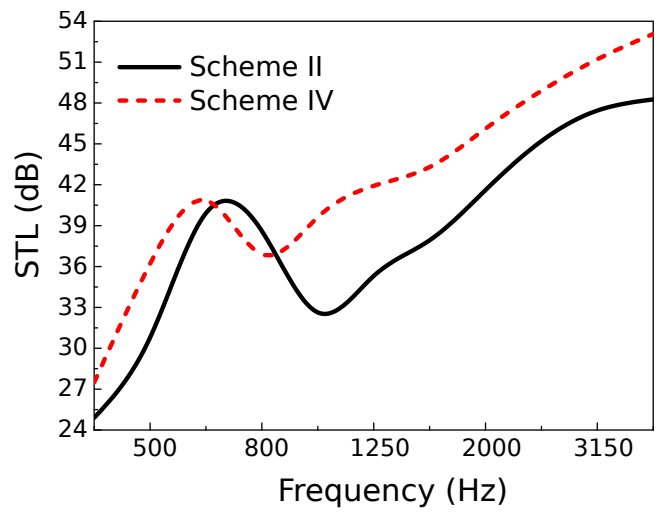

(b)

Figure 13. Influences of damping pasted at MPRR with different positions on STL: (a) STL comparison of Schemes I and III; (b) STL comparison of Schemes II and IV.

ratios, damping pasted at metal panel had a greater influence on STL in the whole frequency (except for individual frequency points) than damping pasted at rib reinforcement.

It's shown in Fig. 13(b) that STL increased by $2.5 \mathrm{~dB}$ on average in the range of $400 \mathrm{~Hz}$ to $630 \mathrm{~Hz}$, and the STL increased by $4.5 \mathrm{~dB}$ on average if the frequency was greater than $800 \mathrm{~Hz}$. However, the STL was reduced by $1.5 \mathrm{~dB}$ on average in the range of $630 \mathrm{~Hz}$ to $800 \mathrm{~Hz}$ by comparing scheme IV with scheme II. It is also seen from Fig. 14 that the damping pasted at metal panel had a greater impact on STL in the whole frequency domain than the damping pasted at rib reinforcement.

\section{(3) Influences of damping pasted at MPRR on STL}

The STL for the MPRR with or without damping material applied was measured in a reverberation-anechoic chamber, and the experimental results are shown in Fig. 14. Two configurations of the objectives were used for study: (i) The coverage area ratio of the damping is $80 \%$ or without damping; (ii) The coverage area ratio of the damping is $100 \%$ or without damping. It's shown in Fig. 14(a) that damping pasted at rib reinforcement (or metal panel) effectively improved the acoustical performance of a MPRR by comparing with no damping treatment. The experimental results show that damping effectively reduced the number of the peak results, or the valley data, for the STL curve of the MPRR.

By comparing Scheme I and Scheme III with Scheme VI, the STL increased by $3.5 \mathrm{~dB}$ on average in the whole frequency (except for the individual frequency points) under damping 


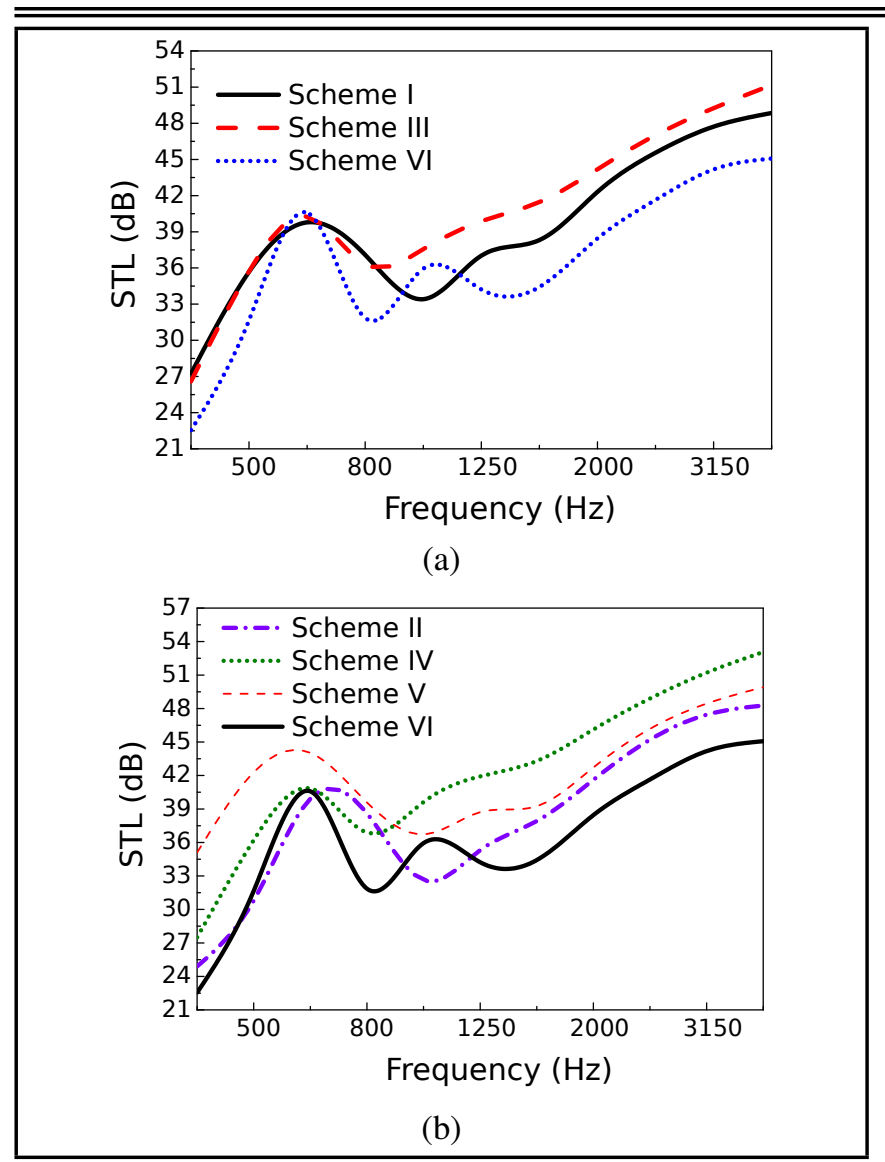

Figure 14. Influences of damping pasted at MPRR on STL: (a) STL comparison of Scheme I, III and VI; (b) STL comparison of Scheme II, IV, V and VI.

pasted at rib reinforcement with $80 \%$ coverage area ratio, and the STL increased by $4.5 \mathrm{~dB}$ on the whole frequency when damping pasted at metal panel over the same coverage area ratio. In addition, the valley result (at $800 \mathrm{~Hz}$ ) for the STL curve of the MPRR can be improved and the frequency point is moved to high frequency.

As shown in Fig. 14(b), damping pasted at rib reinforcement, metal panel or metal panel and rib reinforcement can effectively improve sound insulation performance of the MPRR by comparing with no damping. At the same time, the change of the sound insulation performance was more obvious with the increasing of damping coverage area ratio.

In a word, the influences of coverage area ratio and different positions for damping materials on sound transmission loss (STL) should be considered at the time of using damping materials for acoustic packaging optimization. The optimal acoustic packaging scheme is obtained through the comprehensive analysis of the coverage area ratio and position.

\section{CALCULATION METHODS OF STL FOR MPRR}

\subsection{Modeling of MPRR}

In this section, MPRR IV was taken as a studying example. The model for estimating the STL of a MPRR was presented using commercial software VA-one based on the hybrid FESEA method. The size of a finite element equaled to a quarter

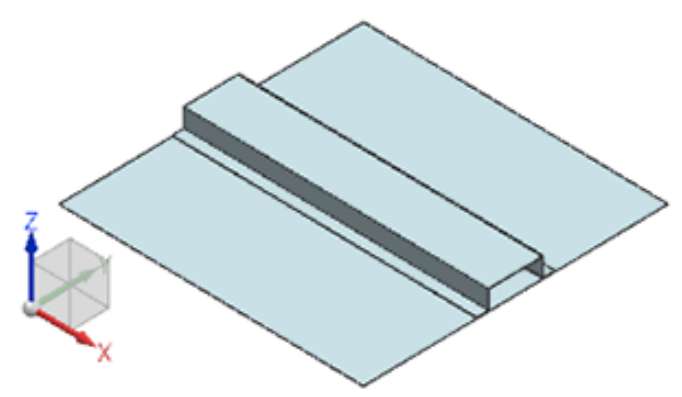

(a)

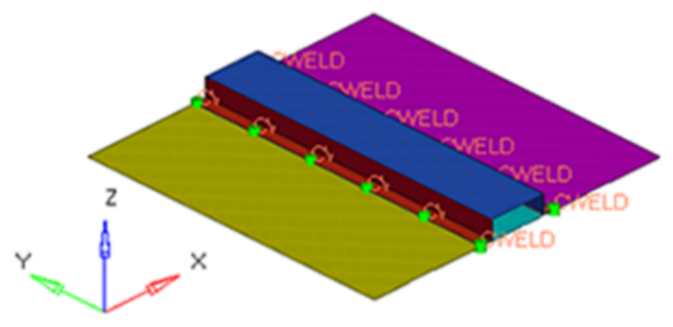

(b)

Figure 15. Model for the MPRR: (a) CAD model; (b) FE model.

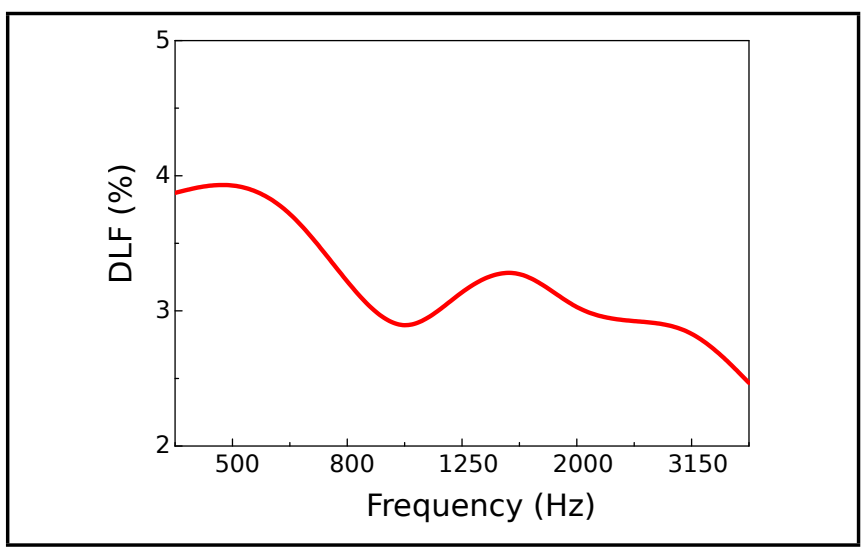

Figure 16. Damping loss factor for the MPRR.

of wavelength, and the welding element was used to characterize the welding between base metal panel and the rib reinforcement. The welding part in MPRR was modeled using the "cweld" element in Hypermesh software, and the frequency domain was assumed as in the range of $0 \mathrm{~Hz}$ to $5 \mathrm{KHz}$. The boundary condition of MPRR was assumed as free boundary. The CAD model and the FE model of the MPRR are shown in Fig. 15. The developed MPRR model was transferred into VAone software, and eight separate "FE subsystems" were created in the model. In the calculation, the mechanic properties for the metal panel shown in Tab. 6 and damping loss factor (DLF) of the MPRR are needed. The DFL was identified using approaches and data processing technology in Ref. ${ }^{23}$ and is shown in Fig. 16.

Table 6. Mechanic properties for metal panel.

\begin{tabular}{|l|l|l|l|}
\hline Material & Density $/\left(\frac{\mathrm{kg}}{\mathrm{m}^{3}}\right)$ & Elastic Modulus /GPa & Poisson's ratio \\
\hline steel & 7850 & 210 & 0.3 \\
\hline
\end{tabular}




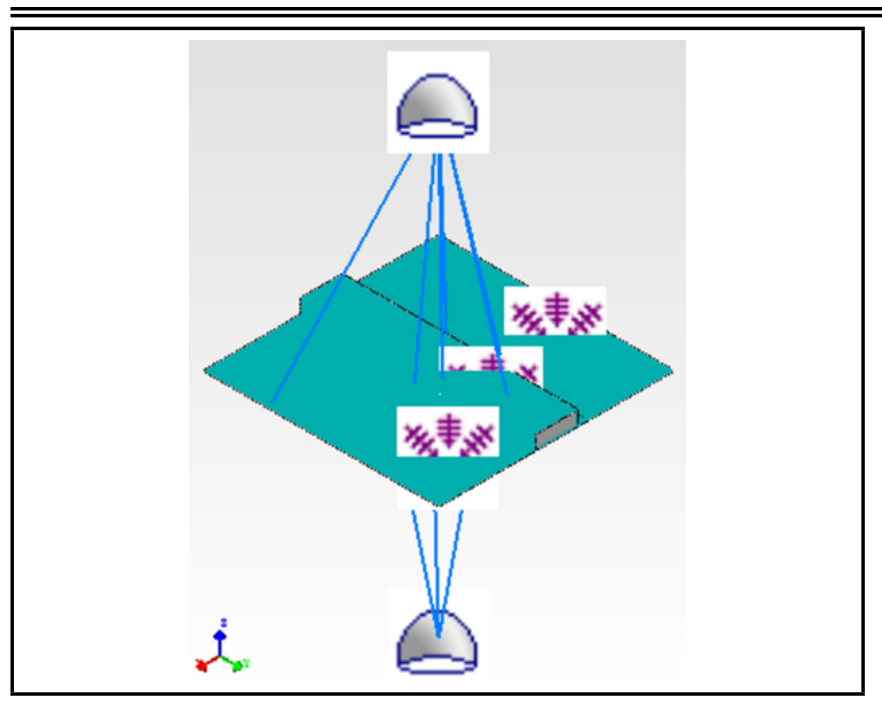

Figure 17. Hybrid FE-SEA model for the MPRR.

The hybrid FE-SEA model of the MPRR is shown in Fig. 17. As shown in the figure, the air between the rib reinforcement and the metal panel formed an acoustic cavity which also served as a path for energy transfer, and the cavity was modeled as an SEA acoustic cavity. The cavity was coupled to the surrounding surfaces using hybrid area connections. The source chambers corresponding to the reverberation chamber and the receiving chambers corresponding to the anechoic chamber were modeled using SEA diffuse acoustic fields and SEA semi-infinite fluids on the source surfaces, separately.

The incident sound power was obtained based on the input pressure and surface area on the source side of the structure. The transmitted sound power was estimated by the sum of all SIFs (Semi-Infinite Fluids). In the following section, a discussion of how to calculate STL is carried out and validated.

\subsection{Model Validations}

In modeling, a pressure was selected for sound source excitation and was set for $1 \mathrm{~Pa}$, and then the incident sound powers (ISPs) $\left(E_{\text {in }}\right)$ were calculated by Eq. (2) and were equal to $1.5 \mathrm{E}-4 \mathrm{~W}$, where the value of $\rho$ and $c$ were equal to $343 \frac{\mathrm{m}}{\mathrm{s}}$ and $1.21 \frac{\mathrm{kg}}{\mathrm{m}^{3}}$, respectively, and $S$ represented the surface area on the source side of the structure. The radiated sound powers (RSPs) $\left(\mathrm{E}_{\text {out }}\right)$ were obtained by the sum of all SIFs (Semi-Infinite Fluids), and the calculated result is shown in Fig. 18. The overall STL of a MPRR was simulated as

$$
S_{T L}=10 \log _{10}\left(\frac{E_{\text {in }}}{E_{\text {out }}}\right) ;
$$

where $\mathrm{E}_{\mathrm{in}}$ and $\mathrm{E}_{\text {out }}$ were the incident sound powers and radiated sound powers in the source chamber and receiving chamber, respectively.

The calculated and the measured STL for MPRR IV are shown in Fig. 19, and It is seen that the calculated results matched the measurements reasonably, which validated the proposed model for MPRR.

However, the calculated data was slightly larger than the tested results in the low frequency range. The reason was

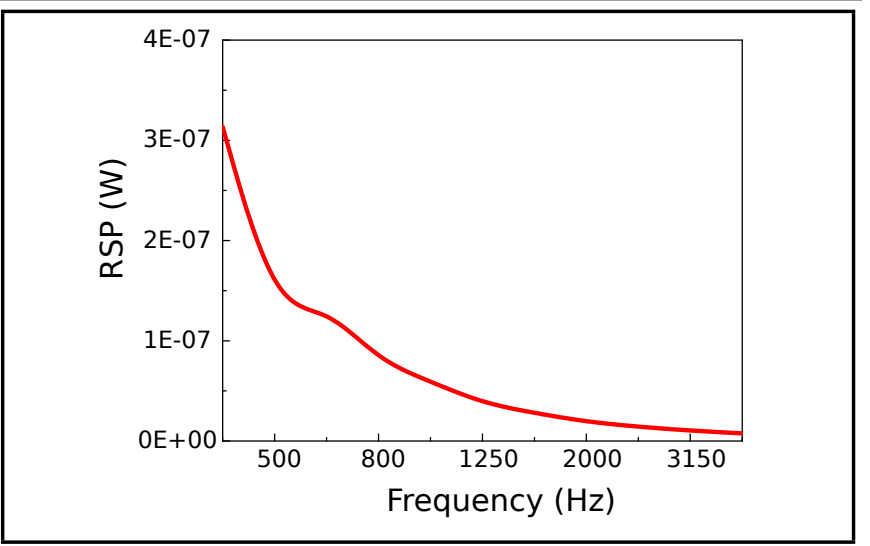

Figure 18. The calculates radiated sound powers.

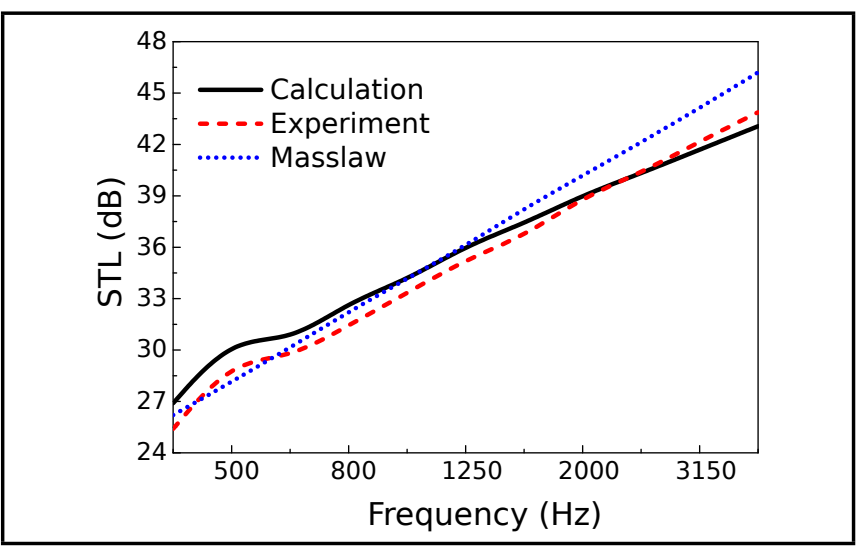

Figure 19. The calculated and measured STL of the MPRR.

that the measured value was affected by the stiffness, damping, boundary conditions, etc., especially in low frequency domain. Also, the assumed free boundary had some deviation from the actual situation, and the calculated natural frequency of the structure was usually larger than the real one, ${ }^{13}$ generating errors between the experimental results and calculation data.

\subsection{Error Analysis of the Calculated STL}

The simulation model in this paper was based on the hybrid FE-SEA method. It is know that if FEM is applied in the analysis of the complex structure dynamics problem, the stiffness matrix of discrete system constructed is usually slightly stiffer, which finally led to the error between the calculated natural frequency and the real one. The errors for the calculated STL of a metal panel with rib reinforcement (MPRR) were usually from boundary condition assumptions and the measured damping loss factors (DLFs) of materials in a MPRR.

\section{(1) Error from boundary condition assumptions}

Three boundary conditions, free boundary, pinned and clamped condition, were assumed in the model for estimating STL of a MPRR In this section, The MPRR IV shown in Fig. 6 was taken as a studying example to analyze the influence boundaries on the estimated results. The degrees of freedom (DOF) for different boundary conditions are shown in Tab. 7.

The STL of the MPRR IV under different boundary conditions are calculated and the estimated results are shown in Fig. 20. 
Table 7. Degree of freedom for different boundary conditions.

\begin{tabular}{|l|l|l|l|l|l|l||}
\hline Boundary & $T_{x}$ & $\mathrm{~T}_{\mathrm{y}}$ & $T_{z}$ & $x$ & $y$ & $z$ \\
\hline Free & $\times$ & $\times$ & $\times$ & $\times$ & $\times$ & $\times$ \\
Pinned & $\checkmark$ & $\checkmark$ & $\checkmark$ & $\times$ & $\times$ & $\times$ \\
Clamped & $\checkmark$ & $\checkmark$ & $\checkmark$ & $\checkmark$ & $\checkmark$ & $\checkmark$ \\
\hline
\end{tabular}

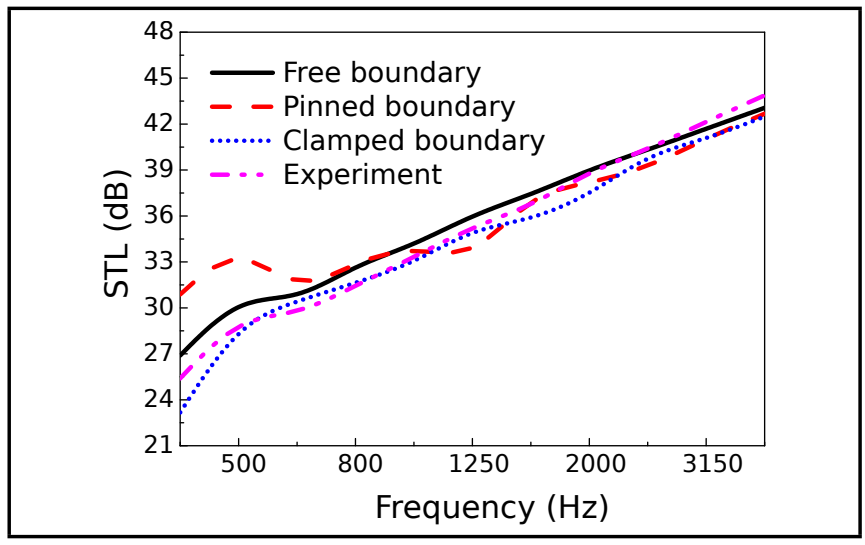

Figure 20. Influences of boundary condition on STL in calculation.

The boundary conditions have a significant effect on the calculated STL, especially in the low frequency range. In fact, the errors between the calculated and the experiment were mainly in the low frequency range. As far as the boundary condition of the MPRR was concerned, the estimated STL under the free boundary condition was in good agreement with the experimental data. The actual installation boundary of a MPRR falls in between the free boundary and the clamped boundary.

\section{(2) Error from measured input parameter of DFL}

The damping loss factor (DLF) of a MPRR is usually obtained through an experimental method. There were measured errors that led to the difference between the simulation and experiment in STL. The MPRR IV was taken as a studying example to analyze the effect of different DLFs on STL. The tested DLFs of the MPRR are shown in Fig. 21(a). The STL of the MPRR with different DLFs under free boundary condition were calculated and are shown in Fig. 21(b). As the figure indicated, the DLF have great effect on STL in low frequency domain.

\subsection{Applications}

In this section, the STL for MPRR V and MPRR VI were simulated based on the calculation model established in section 3.1 and validated by experiment, and the calculation results are shown in Fig. 22 and Fig. 23, respectively.

As shown in Fig. 22 and Fig. 23, the calculation results were consistent with the experimental results, and the prediction accuracy meets the engineering requirements. Therefore, the proposed model for simulating the sound insulation performance of a MPRR can be used to calculate STL.

\section{CONCLUSIONS}

Influence of rib reinforcement and pasted damping on sound insulation performances of a metal panel are disclosed, and the following conclusions are obtained.

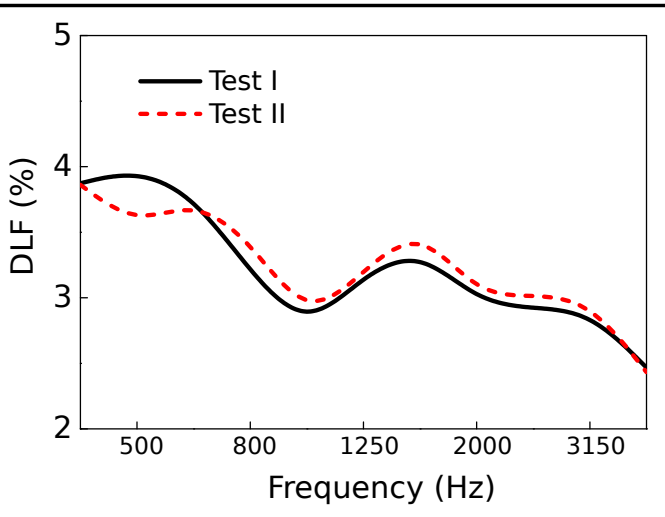

(a)

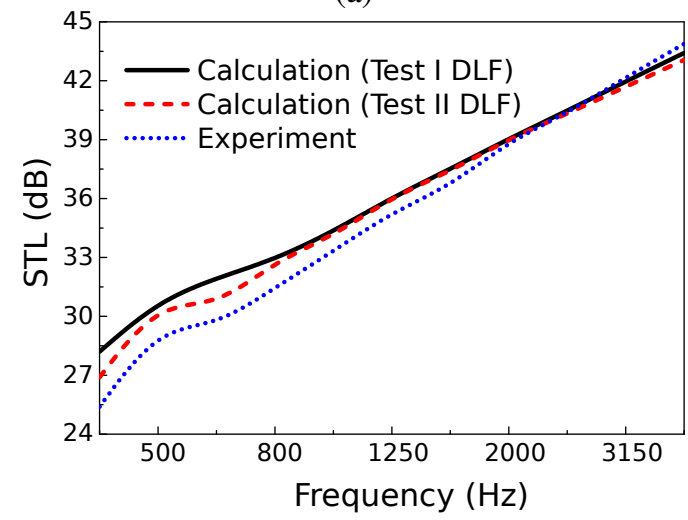

(b)

Figure 21. Influence of measured error for DLF on STL calculation: (a) The measured DLF; (b) The calculated STL under different DLF.

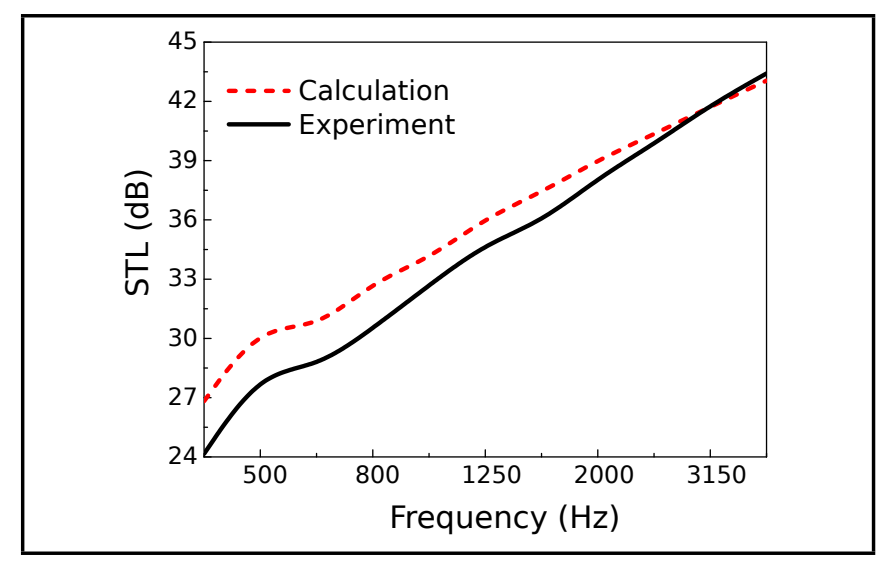

Figure 22. STL of the MPRR V.

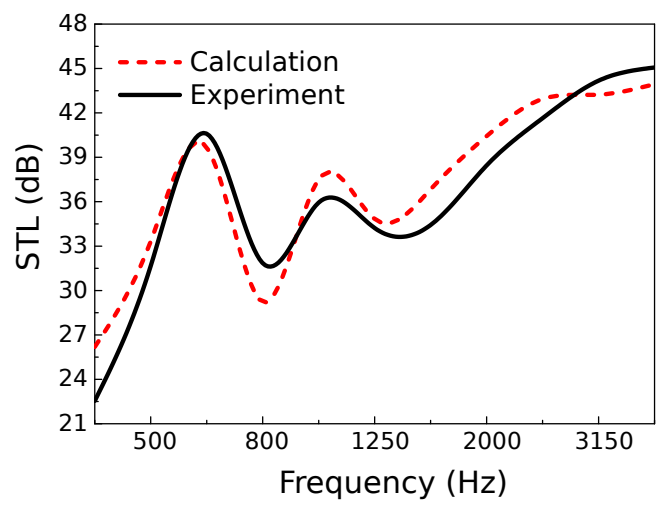

Figure 23. 23 STL of the MPRR VI. 
(1) Both the height and width of rib reinforcement have a great influence on the STL of a metal panel. The influence of height on metal panel STL only occurs at certain frequency ranges, whereas increasing the width can increase metal panel STL at whole frequency ranges. As the number of rib reinforcement increased, the metal panel STL increased greatly around one frequency due to cavity resonance.

(2) The pasted damping at a MPRR has significant effects in its STL, and different damping pasted at different locations and different coverage areas have different effects. Increasing pasted damping can increase MPRR's STL.

(3) In calculating the STL of a MPRR, the boundary condition has great influences on the estimated error with measurement, and warrants close attention during modeling.

\section{FUTURE WORK}

It has been found in this paper that research has been carried out on the sound insulation performance of the MPRR, but very limited research has been done on the analysis of treatment of damping materials in commercial software. Some potential areas have been identified for future research as briefed below:

(1) The six MPRR samples presented in this paper represent the widely used structures of the automobile dash panel system. In the next step, the authors will investigate other configurations to achieve at least a $3 \mathrm{~dB}$ difference based on the existing research foundation.

(2) Since the commercial software cannot be used for analyzing the treatment of damping materials, simulations on samples with damping treatment cannot be done at present. But this is a good suggestion for our future research.

\section{ACKNOWLEDGEMENTS}

We gratefully acknowledge to the finically support from the support from the Natural Science Foundation of Guangdong Province (2019A1515011612). The authors are grateful to Ningbo Tuopu Group Co., Ltd. for the manufacture of the MPRR samples, and experiments are made by acoustic laboratory of Ningbo Tuopu Group Co., Ltd., China.

\section{REFERENCES}

1 P. Thamburaj, J. Q. Sun. Effect of Material Anisotropy on the Sound and Vibration Transmission Loss of Sandwich Aircraft Structures, Journal of Sandwich Structures and Materials, 1(1), 76-92, (1999). https://dx.doi.org/10.1177/109963629900100105

2 C. J. Christopher, P. Wennhage, P. Goransson. Structuralacoustic Design of a Multi-functional Sandwich Panel in an Automotive Context, Journal of Sandwich Structures and Materials, 12(6), 684-708, (2010). https://dx.doi.org/10.1177/1099636209359845

3 P. Shorter, Q. Zhang, A. Parrett. Using the hybrid FESEA method to predict and diagnose component transmission loss. SAE Technical Paper 2007-01-2172, (2007). https://dx.doi.org/10.4271/2007-01-2172
4 T. E. Vigran. Normal incidence sound transmission loss in impedance tube -Measurement and prediction methods using perforated plates, Applied Acoustics, 73, 454-459, (2012). https://dx.doi.org/10.1016/j.apacoust.2011.11.009

5 S. Du, F. An, B. Liu. On the sound transmission loss of finite plates with constrained viscoelastic layer, Applied Acoustics, 149, 32-38, (2019). https://dx.doi.org/10.1016/j.apacoust.2019.01.010

6 F. Errico, G. Tufano, O. Robin, et al. Simulating the sound transmission loss of complex curved panels with attached noise control materials using periodic cell wave modes, Applied Acoustics, 156, 21-28, (2019). https://dx.doi.org/10.1016/j.apacoust.2019.06.027

7 G. Maidanik. Response of ribbed panels to reverberant acoustic fields, Journal of the Acoustical Society of America, 34(6), 809-826, (1962). https://dx.doi.org/10.1121/1.1918200

8 A. C. Nilsson. Wave propagation in and sound transmission through sandwich plates. Journal of Sound and Vibration, 138(1), 73-94, (1990). https://dx.doi.org/10.1016/0022460X(90)90705-5

9 E. Nilsson, A. C. Nilsson. Prediction and measurement of some dynamic properties of sandwich structures with honeycomb and foam cores. Journal of Sound and Vibration, 251(3), 409-430, (2002). https://dx.doi.org/10.1006/jsvi.2001.4007

10 D. Backstrom, A. C. Nilsson. Modelling the vibration of sandwich beams using frequency-dependent parameters. Journal of Sound and Vibration, 300(3-5), 589-611, (2007). https://dx.doi.org/10.1016/j.jsv.2006.07.048

11 A. Santoni, P. Bonfiglio, F. Mollica, et al. Vibro-acoustic optimisation of Wood Plastic Composite systems. Construction and Building Materials, 174, 730-740, (2018). https://dx.doi.org/10.1016/j.conbuildmat.2018.04.155

12 N. Atalla. Modeling the sound transmission through complex structures with attached noise control materials. Wave Motion, 51(4): 650-663, (2014). https://dx.doi.org/10.1016/j.wavemoti.2013.11.001

13 M. P. Arunkumar, J. Pitchaimani, K. V. Gangadharan et al. Sound transmission loss characteristics of sandwich aircraft panels: Influence of nature of core, Journal of Sandwich Structures and Materials, 19(1), 26-48, (2017). https://dx.doi.org/10.1177/1099636216652580

14 Z. H. Wen, D. W. Wang, L. Ma. Sound transmission loss of sandwich panel with closed octahedral core, Journal of Sandwich Structures and Materials, (2019). https://dx.doi.org/10.1177/1099636219829369 
15 W. Li, Y. He, Z. Xu et al. Sound transmission loss characteristics of four-side simply supported sandwich panels, Journal of Sandwich Structures and Materials, 21(2), 707-726, (2019). https://dx.doi.org/10.1177/1099636217698394

16 P. Oliazadeh, A. Farshidianfar. Analysis of different techniques to improve sound transmission loss in cylindrical shells, Journal of Sound and Vibration, 389, 276-291, (2017). https://dx.doi.org/10.1016/j.jsv.2016.11.016

17 P. Oliazadeh, A. Farshidianfar, M. J. Crocker. Experimental and analytical investigation on sound transmission loss of cylindrical shells with absorbing material, Journal of Sound and Vibration, 434, 28-43, (2018). https://dx.doi.org/10.1016/j.jsv.2018.07.017

18 P. Oliazadeh, A. Farshidianfar, M. J. Crocker. Study of sound transmission through single- and double-walled plates with absorbing material: Experimental and analytical investigation. Applied Acoustics, 145, 7-24, (2019). https://dx.doi.org/10.1016/j.apacoust.2018.09.014

19 E. Deckers, O. Atak, L. Coox, et al. The wave based method: an overview of 15 years of research. Wave Motion, 51(4), 550-565, (2014). https://dx.doi.org/10.1016/j.wavemoti.2013.12.003

20 G. R. Liu, K. Y. Dai, T. T. Nguyen. A smoothed finite element method for mechanics problems, Computational Mechanics, 39(6), 859-877, (2007). https://dx.doi.org/10.1007/s00466-006-0075-4

21 F. Wu, G. R. Liu, G.Y. Li, et al. A coupled ES-BEM and FM-BEM for structural acoustic problems. Noise Control Engineering Journal, 62(4), 196-209, (2014). https://dx.doi.org/10.3397/1/376220

22 F. Wu, Y. J. Chen, L. Y. Yao, et al. The development of hybrid ES-FE-SEA method for mid-frequency vibration analysis of complex built-up structure. Applied Mathematical Modeling, 64, 298-319, (2018). https://dx.doi.org/10.1016/j.apm.2018.07.033

23 S. Dey, D. K. Datta, J. J. Shirron, et al. P-Version FEM for structural acoustics with a posteriori error estimation. Computer Methods in Applied Mechanics and Engineering, 195(17), 1946-1957, (2006). https://dx.doi.org/10.1016/j.cma.2004.11.030

24 I. Harari, F. Magoulès. Numerical investigations of stabilized finite element computations for acoustics. Wave Motion, 39(4), 339-349, (2004). https://dx.doi.org/10.1016/j.wavemoti.2003.12.001

25 C. Farhat, I. Harari, U. Hetmaniuk. A discontinuous Galerkin method with Lagrange multipliers for the solution of Helmholtz problems in the mid-frequency regime. Computer Methods in Applied Mechanics and Engineering, 192(11), 1389-1419, (2003). https://dx.doi.org/10.1016/S0045-7825(02)00646-1
26 M. J. Crocker, A. J. Price. Sound transmission using statistical energy analysis. Journal of Sound and Vibration, 9(3), 469-486, (1969).

27 A. J. Price, M. J. Crocker. Sound transmission through double panels using statistical energy analysis. Journal of the Acoustical Society of America, 3(1), 683-693, (1970). https://dx.doi.org/10.1121/1.1911951

28 P. Rouch, P. Ladevèze. The variational theory of complex rays: a predictive tool for medium-frequency vibrations. Computer Methods in Applied Mechanics and Engineering, 192(28), 3301-3315, (2003). https://dx.doi.org/10.1016/S0045-7825(03)00352-9

29 B. Mace. Statistical energy analysis, energy distribution models and system modes. Journal of Sound and Vibration, 264(2), 391-409, (2003). https://dx.doi.org/10.1016/S0022-460X(02)01201-4

30 L. Ji, X. Sheng, X. Xiao, et al. A review of midfrequency vibro-acoustic modelling for high-speed train extruded aluminium panels as well as the most recent developments in hybrid modelling techniques. Journal of Modern Transportation, 23(3), 159-168, (2015). https://dx.doi.org/10.1007/s40534-015-0080-4

31 R. S. Langley, V. Cotoni. Response variance prediction for uncertain vibro-acoustic systems using a hybrid deterministic-statistical method. The Journal of the Acoustical Society of America, 122(6), 3445-3463, (2007). https://dx.doi.org/10.1121/1.2799499

32 A. Cicirello, R. S. Langley. The vibro-acoustic analysis of built-up systems using a hybrid method with parametric and non-parametric uncertainties. Journal of Sound and Vibration, 332(9), 2165-2178, (2013). https://dx.doi.org/10.1016/j.jsv.2012.05.040

33 O. Robin, A. Berry. Estimating the sound transmission loss of a single partition using vibration measurements. Applied Acoustics, 141, 301-306, (2018). https://dx.doi.org/10.1016/j.apacoust.2018.07.015

34 M. J. Crocker, P. K. Raju, B. Forssen. Measurement of transmission loss of panels by direct determination of transmitted Intensity. Noise Control Engineering, 17(1), 6-11, (1981).

35 ISO 15186-1. Acoustics - Measurement of Sound Insulation in Buildings and of Building Elements using sound intensity probe Part 1: Laboratory measurements. International Organization for Standardization, Geneva, (2000).

36 O. Doutres, N. Atalla. Experimental estimation of the transmission loss contributions of a sound package placed in a double wall structure, Applied Acoustics, 72, 372-379, (2011). https://dx.doi.org/10.1016/j.apacoust.2010.12.011 